\title{
INVESTIGATION OF PEDESTRIAN CHARACTERISTIC FLOW IN MIXED TRAFFIC CONDITION A CASE STUDY IN ELECTRONIC CITY TO MADIWALA
}

\author{
M. Durga \\ Civil Engineering Department, \\ Noida international university, Greater Noida, India \\ Dr. Paritosh Srivastava \\ Associate Professor, HOD -Civil Engineering, \\ Noida International University (NIU), Greater Noida, India

\section{Dr. A. Shanmuganathan} \\ Associate Professor, Director of School of Engineering \& Technology, \\ School of Engineering \& Technology, Noida International University, India
}

\begin{abstract}
In this research, mixed methodology has when utilised for data collection through which a wide range of the has been collected. The process of survey among 199 citizens has been utilised for qualitative data analysis whereas interviews among 4 Traffic officers adapted for collecting qualitative data. Therefore, for primary research, a thorough analysis using graphs and charts have provided adequate scope of evaluation. For secondary data, qualitative thematic analysis has been taken into consideration for effective assessment of data regarding pedestrian characteristics in Madiwala in terms of traffic condition.
\end{abstract}

Keywords: Intergrated Water Resources Management (IWRM), Sustainable management, Water resources

Cite this Article: M. Durga, Paritosh Srivastava and A. Shanmuganathan, Investigation of Pedestrian Characteristic Flow in Mixed Traffic Condition a Case Study in Electronic City io Madiwala, International Journal of Civil Engineering and Technology, 11(9), 2020, pp. 62-76.

https://iaeme.com/Home/issue/IJCIET?Volume=11\&Issue=9 


\section{INTRODUCTION}

The process of data analysis aids in assessment of collected data through which useful information can be integrated about a specific topic. In this research, mixed methodology has when utilised for data collection through which a wide range of the has been collected. The process of survey among 199 citizens has been utilised for qualitative data analysis whereas interviews among 4 Traffic officers adapted for collecting qualitative data. Therefore, for primary research, a thorough analysis using graphs and charts have provided adequate scope of evaluation. For secondary data, qualitative thematic analysis has been taken into consideration for effective assessment of data regarding pedestrian characteristics in Madiwala in terms of traffic condition.

\section{QUANTITATIVE DATA ANALYSIS}

\subsection{Target Groups Engaged in Bangalore Traffic}

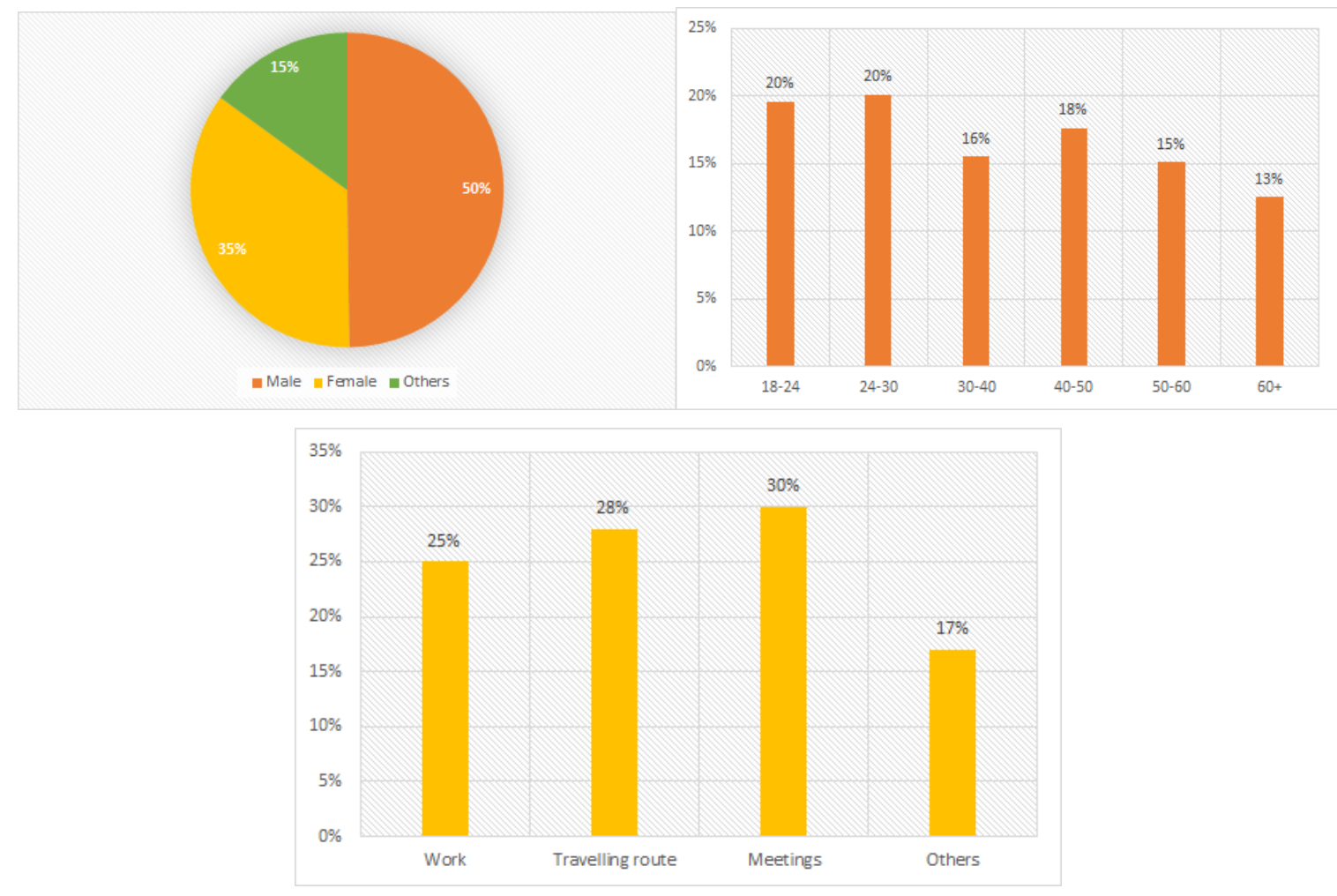

Figure 1

In terms of qualitative data analysis, the survey revealed $50 \%$ male and $35 \%$ female participants and $15 \%$ did not reveal their identity. Among these participants, $20 \%$ participants were of 18-24 and 24-30 years of age each. On the other hand, 18\% belonged to $40-45 \%$ whereas $16 \%$ to $30-40$ years of age. The rest $30 \%$ consisted of people more than 50 years of age. An equal footing of male and female dominated drivers was also identified in this research.

Upon asking the participants about your purpose of visiting the electronic city of Madiwala, it has been identified that $30 \%$ of the participants engage in meetings while for $28 \%$ it's in the travelling route. The rest $25 \%$ attended for work and rest $17 \%$ caters to other reasons. The last number of visitations is because this city houses various prestigious institutions such as Infosys and Wipro (Subrahmanya, 2017). Due to this aspect, people 
visited Bangalore on a regular basis which resulted in the high influx of population which catered towards congested traffic in Bangalore.

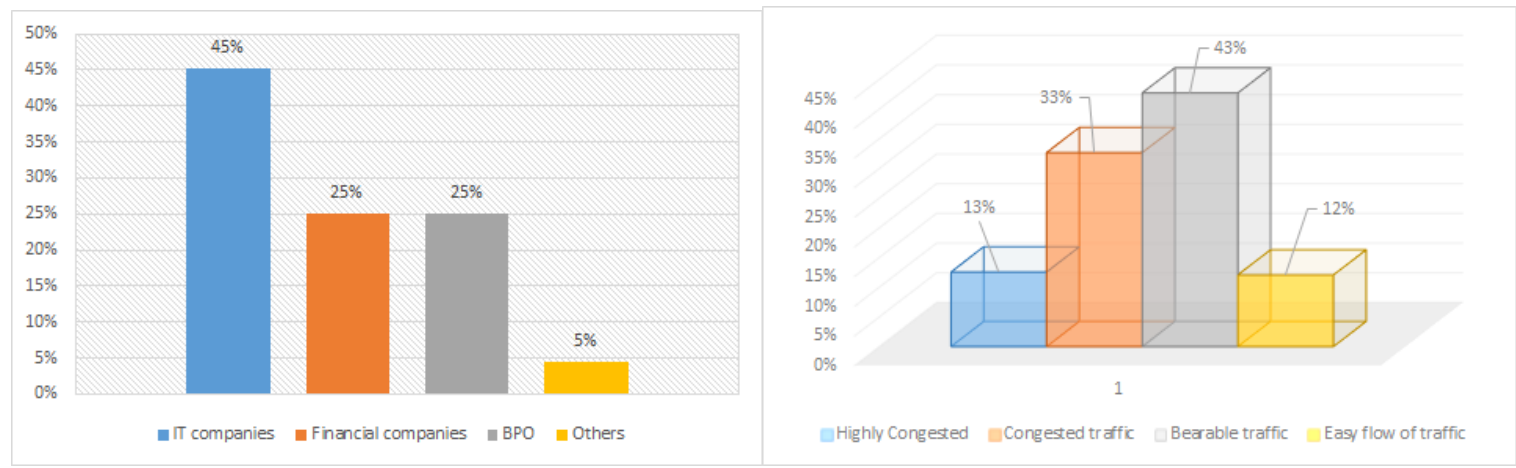

Figure 2

The fourth question catered towards understanding the type of organisation the participants were engaged in. $45 \%$ worked for IT companies, $25 \%$ for financial where $25 \%$ in BPO and rest $5 \%$ participants in other sectors. The fifth question was focused on understanding the traffic in the City where $43 \%$ answered it was bearable while $33 \%$ agreed it was congested. From this assessment, it can be stated that more traffic is because of the city's environment and the presence of Highway is the road connecting to the industrial hub.

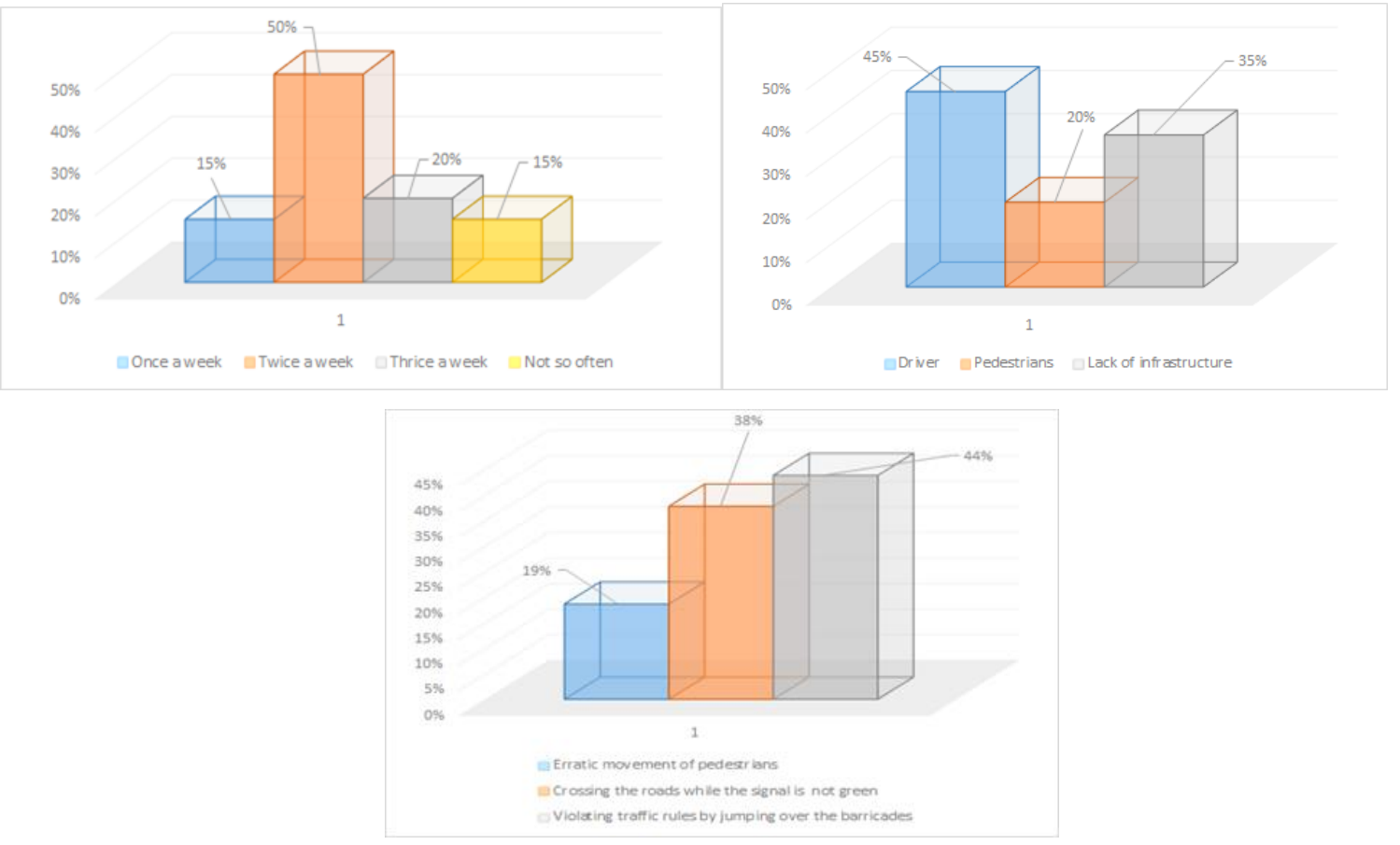

Figure 3

On evaluation of the number of accidents, it was identified that $50 \%$ agreed accidents twice a week while $20 \%$ agreed it was thrice. The participants believed that $45 \%$ of these accidents were caused by drivers $35 \%$ was due to lack of infrastructure. On the other hand20\% was caused by pedestrians. The reason behind this accident identifies to be not following up traffic signals by $38 \%$ where is violation of traffic rules by $44 \%$. $19 \%$ agreed that erratic movements of pedestrians were the results of such accidents. Therefore, lack of uncontrolled speed and improper supervision can be identified as the reasons behind the increasing accident (Bbc.com, 2016). 


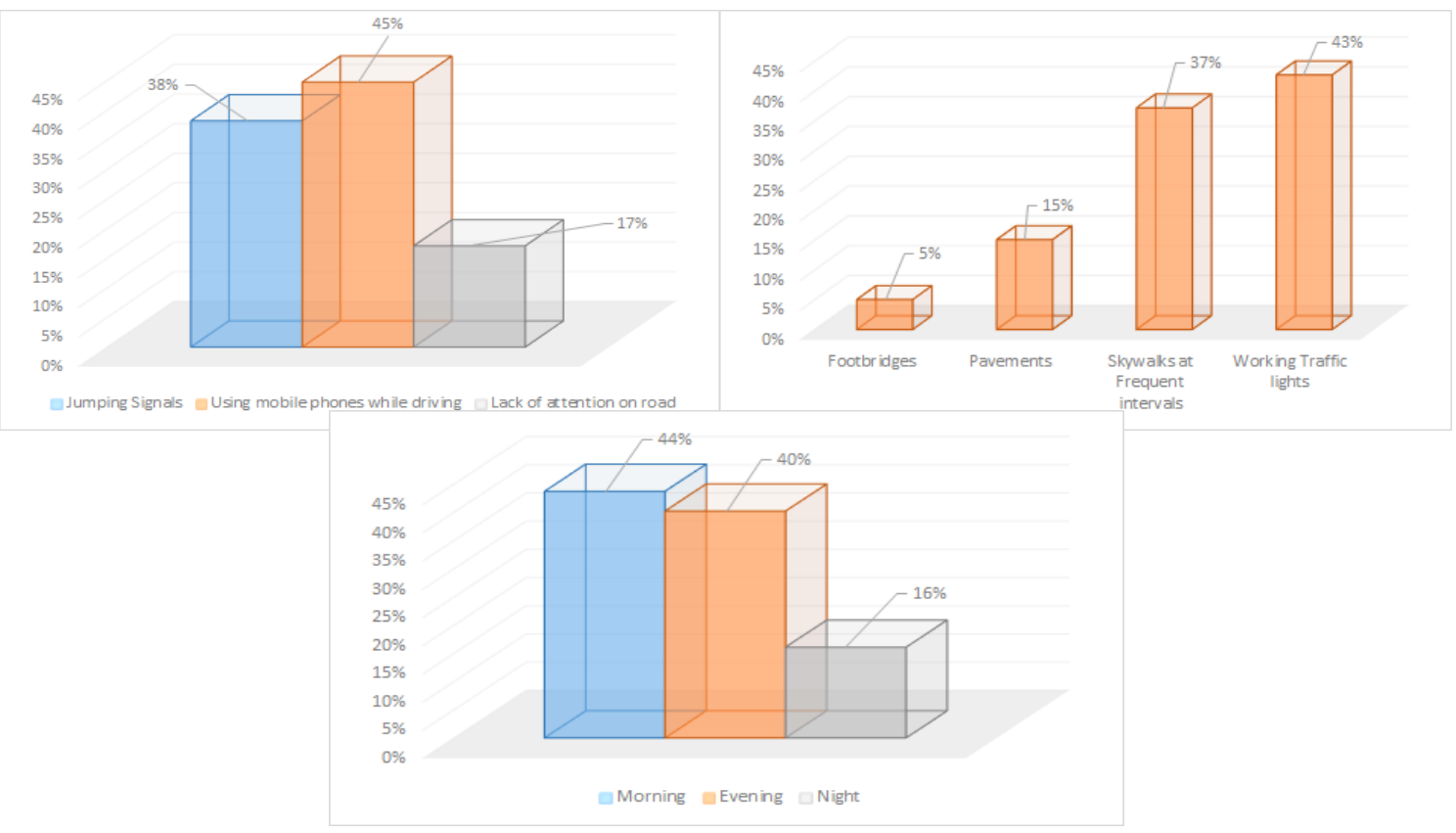

Figure 4

The participants in the survey stated that $38 \%$ accidents caused by drivers because of jumping signals while $45 \%$ because of using mobile phones and $17 \%$ because of the lack of attention. Infrastructure, $37 \%$ believed lack of skywalks, $15 \%$ agreed that lack of pavement and 5\% lack of footbridge is resulting in the accidents in Madiwala. Upon further assessment, $44 \%$ participants believe accidents occurred in the morning because of the heavy traffic in respect to office goers and educational institutions. $40 \%$ accidents of 8 in the evening was $15 \%$ at night.

\subsection{Factors impacting the increased rate of accidents within the electronic city of} Madiwala
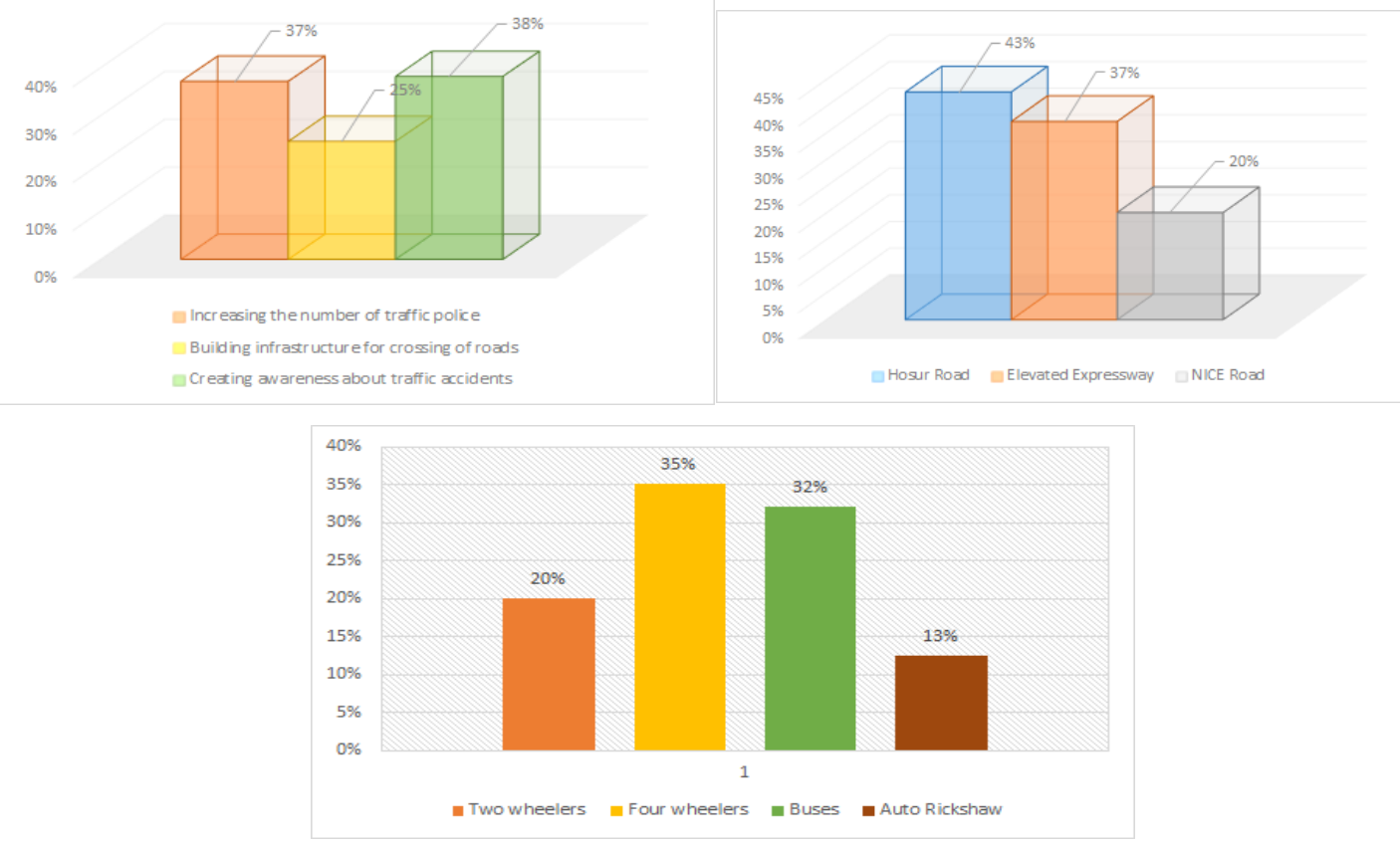

Figure 5 
Due to the increasing number of accidents in the electronic city, $37 \%$ believe that increasing the number of traffic police can aid the cause. The rest $38 \%$ believe creating awareness about traffic rules can be the solution to the problem whereas $25 \%$ agree that appropriate infrastructure for crossing the road then prove to be beneficial. $43 \%$ participants believe Hosur road to be the main cause of the accidents while $37 \%$ believe it to be the elevated expressway. Therefore, adequate measurements can be taken in respect to the vehicles utilised where 35\% agree it is four-wheelers, $32 \%$ in bus whereas $20 \%$ to be twowheelers.

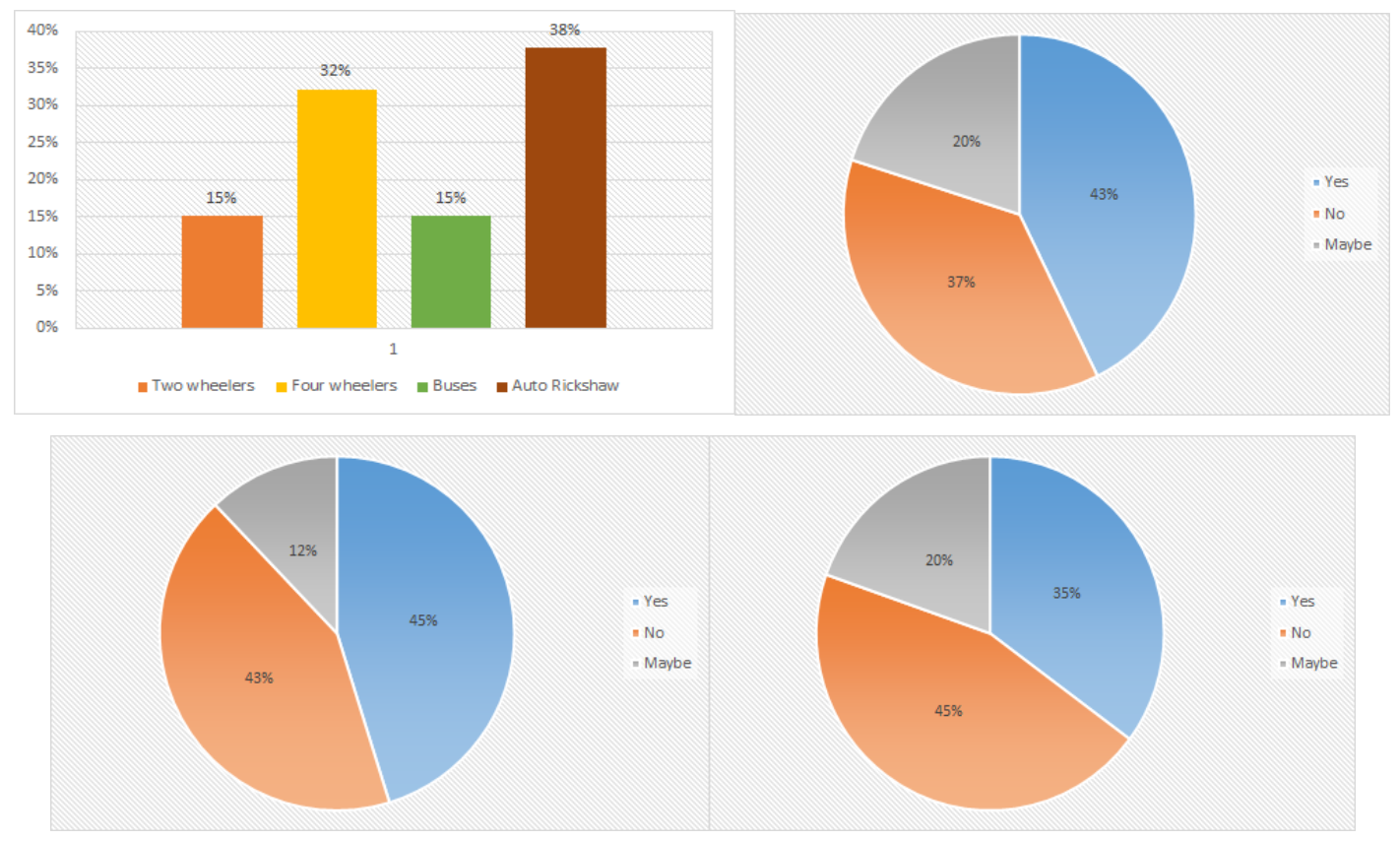

Figure 6

$32 \%$ agree that most accidents are caused by four-wheelers, $38 \%$ by auto-rickshaw followed by $30 \%$ by bus and two-wheelers at equal rate. $43 \%$ agreed that lack of traffic officers in Madiwala resulted in the accidents. $45 \%$ believed that accidents in Hosur road were the main fault of drivers and $35 \%$ believed pedestrians jaywalking on the road resulted in the accidents. Therefore, as influenced by Hooftman et al. (2018), the need for strict regulatory measurements for vehicles as well as citizens are needed. Through this, the high rate of accidents can be kept under control.

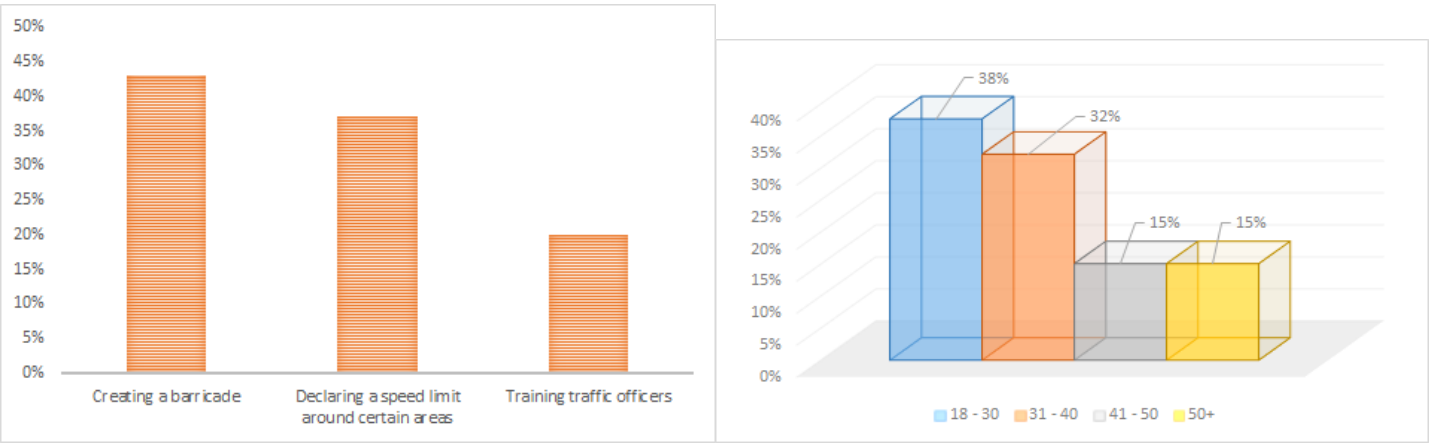




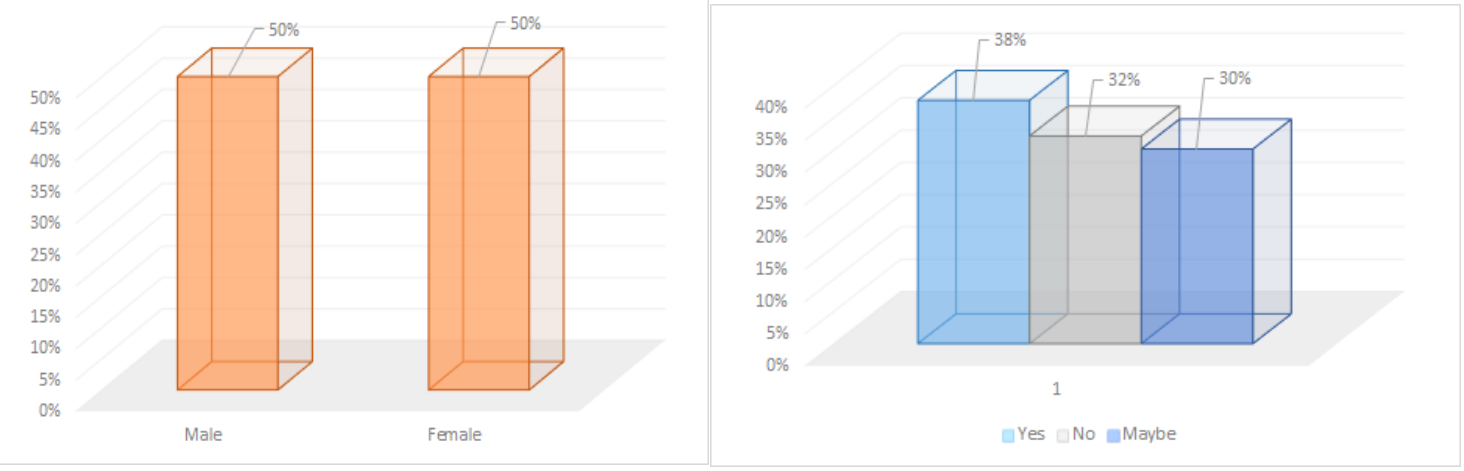

Figure 7

43\% participants believe that creating a barricade would result in prevention of accidents around Hosur Road. 37\% believe implementation of speed limits such as restriction of $40 \mathrm{Kmph}$ by $20 \%$ great training of traffic officers can be beneficial for accident prevention. Further assessment led to the understanding of recklessness of young-drivers of 18-30 years of age due to which most accidents occur as per $38 \%$. This is followed by $32 \%$ agreeing that 31-50 years are the main cause. Both 50\% male and female have been identified to be prone to accidents and $38 \%$ believe the time gap between the signals result in the increase of such problems. Due to this, modifications in terms of traffic significance can help in improvement of the present situation in Madiwala.

\subsection{Understanding participant's view on road traffic and accidents}

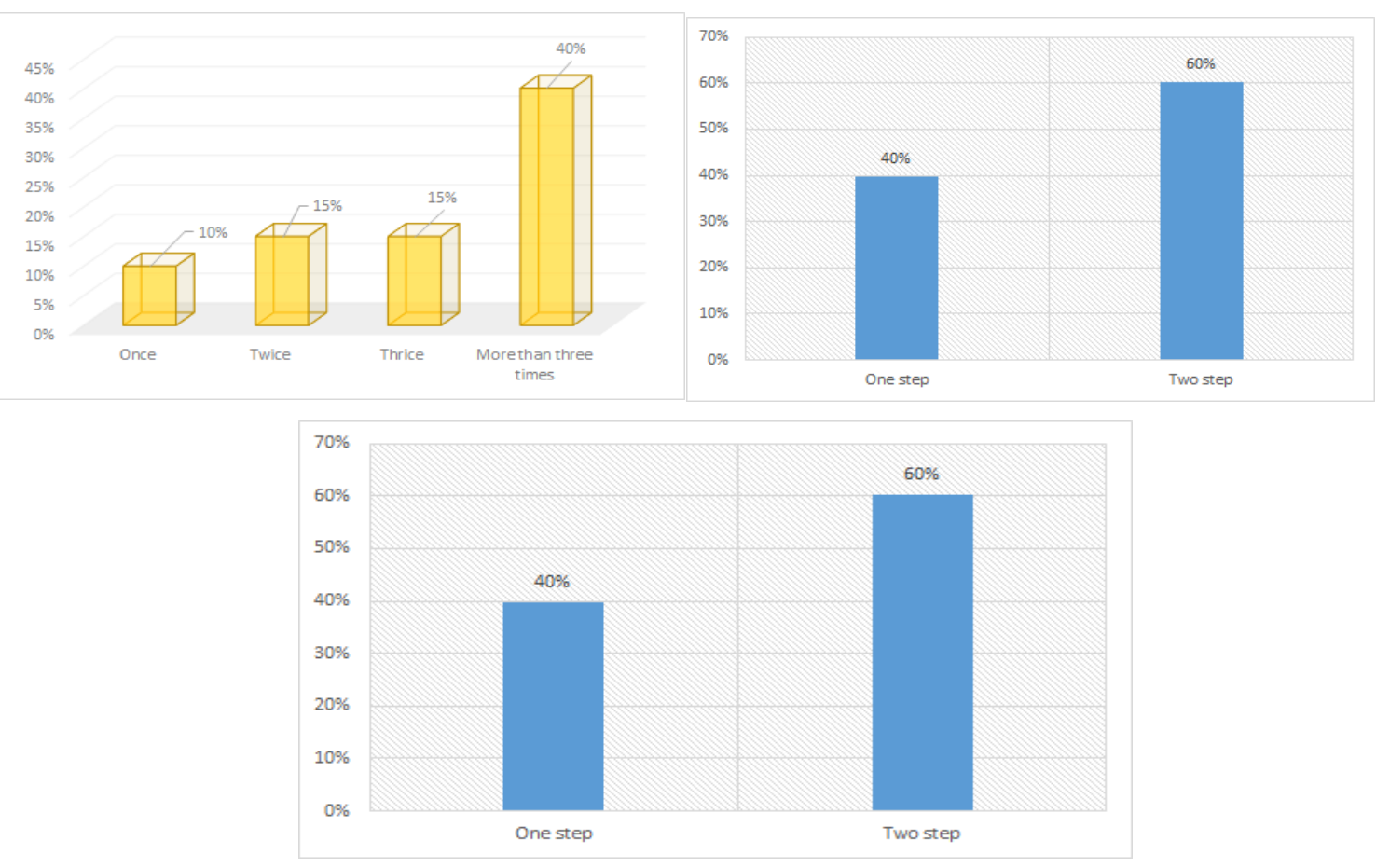

Figure 8

The next questions delved in a more personal level by catering towards the participants in involvement with accidents. $40 \%$ stated that they have faced accidents more than three times whereas $30 \%$ have faced it twice and thrice equally. $60 \%$ asserted that they cross roads by taking two-steps while $40 \%$ take one-step. Therefore, the impact of crossing patterns in terms 
of accidents can be evaluated since 55\% agreed that they have an impact. Careful evaluation can lead to reforming of regulations through which appropriate measurements such as proper appropriate infrastructure can be established (Bbc.com, 2016).

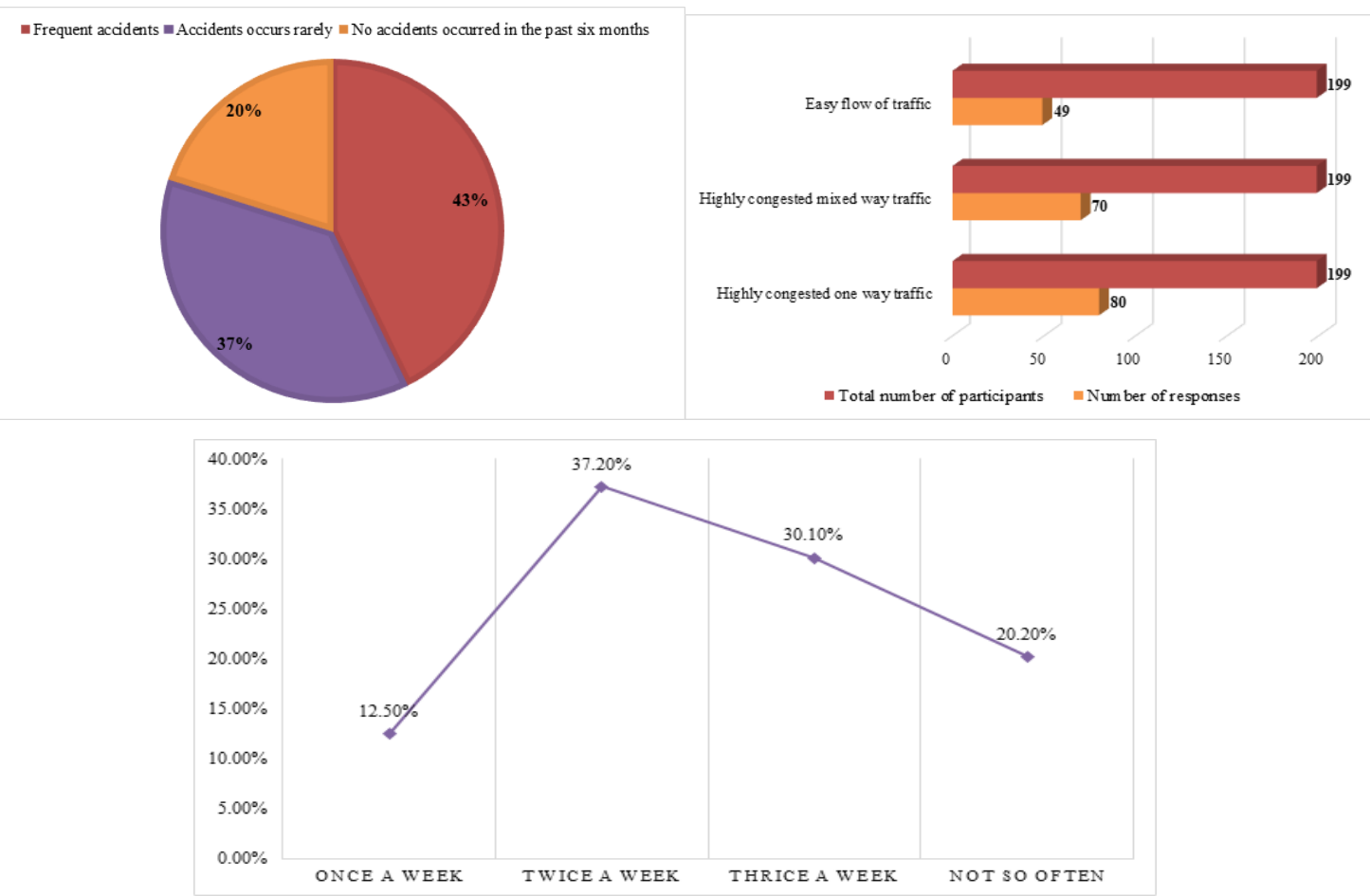

Figure 9

In Madiwala, the rate of frequent accidents has been agreed upon by $42.8 \%$ of participants while $37 \%$ believed they occurred rarely. $40.2 \%$ believed the reason was highly congested one-way traffic whereas $35.1 \%$ believed it was because of mixed-way traffic. Almost $30 \%$ stated that the accident occurs thrice a week and $37 \%$ believe it occurs twice a week near Madiwala. According to this rate, urgent measurements can be deemed as necessary.
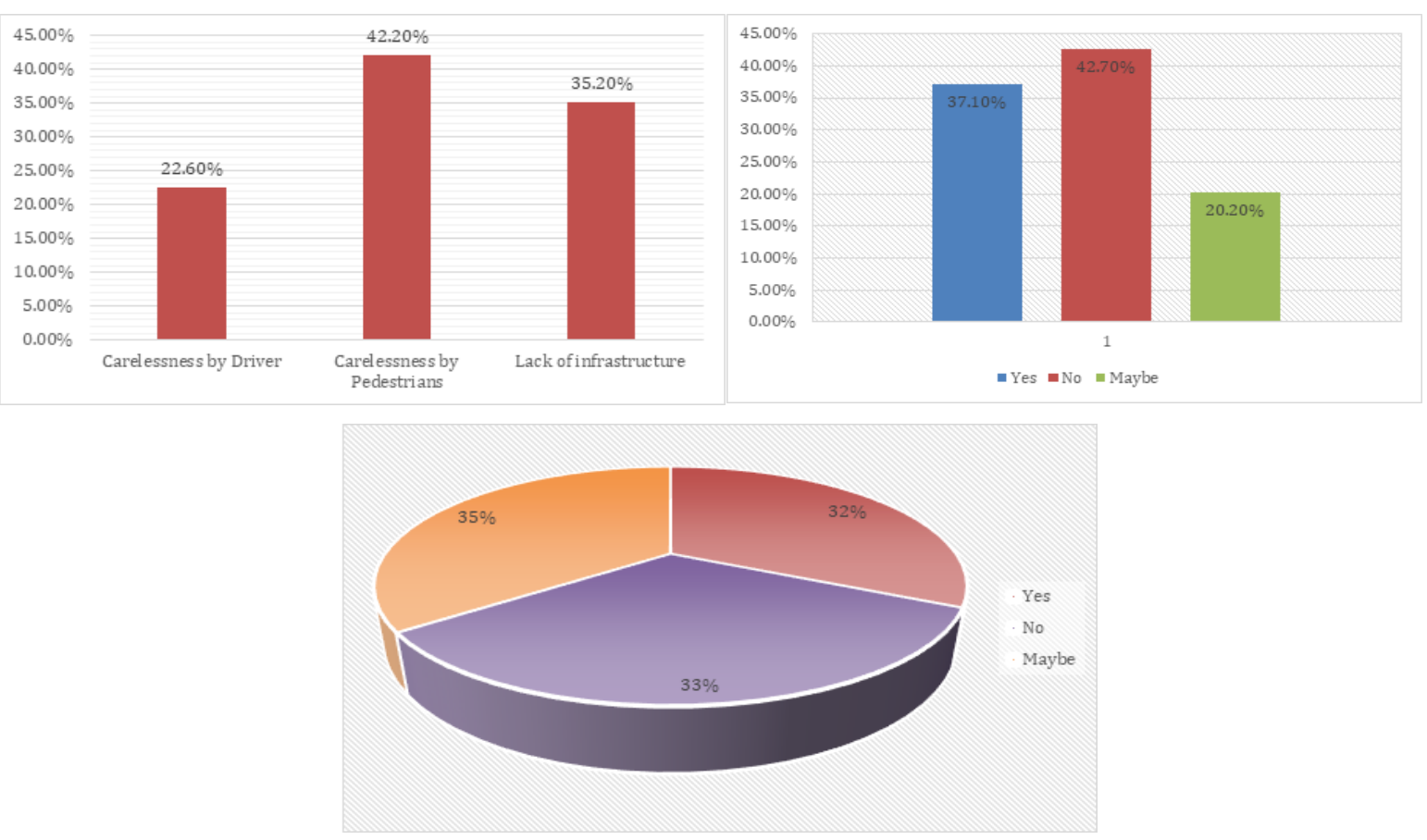

Figure 10 
According to the participants, carelessness of drivers constitutes about $22.6 \%$ of accidents whereas carelessness resulted in $42.2 \%$ of accidents. $35.2 \%$ agreed that lack of infrastructure is the main cause. This aspect in terms of pedestrians caters to accidents as agreed upon by 30 $7.1 \%$ of participants. However, a neutral point of view has been observed in regards to pedestrians' movement in terms of accidents. Despite this factor, traffic related activities are required to be kept under strict supervision in Madiwala.

\subsection{Determination of time-assessment catering towards accidents}

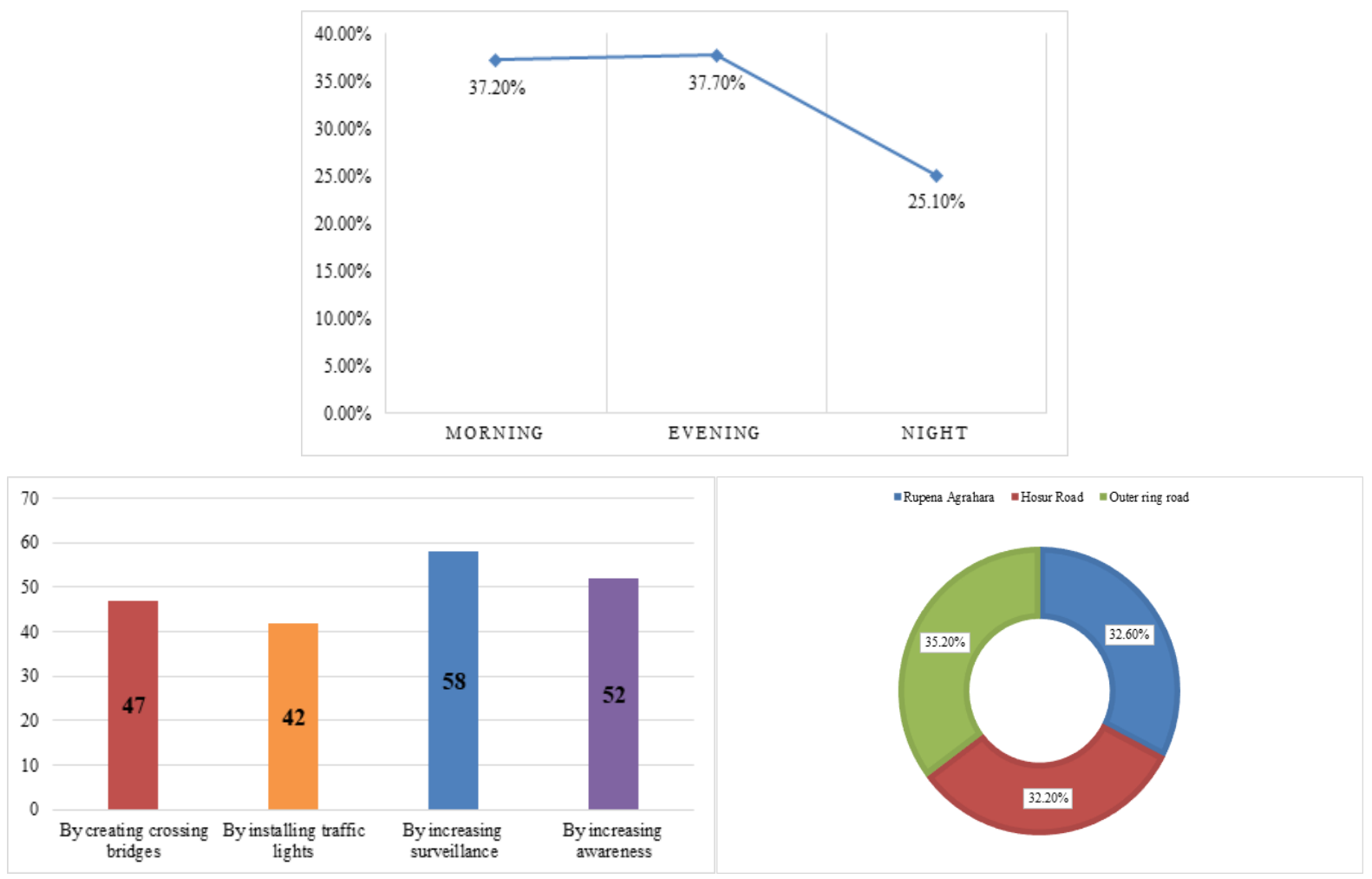

Figure 11

The survey helped us understand the traffic conditions of Madiwala which were considered to be more in the morning as compared to the evening and night. For mitigation of traffic accidents $29.1 \%$ believe increasing surveillance and $26.2 \%$ agreed that raising awareness can be helpful for accident prevention. $23.6 \%$ believe that crossing bridges while $21.1 \%$ agreed that installing traffic lights can prove to be fruitful. On further assessment $35.2 \%$ agree Outer ring road in Maniwala is more prone to accidents, 32\% agree it to be Hosur road and 32.6\% Roopena Agrahara road to be the main cause. Therefore, the importance of proper infrastructure can be deemed as necessary.

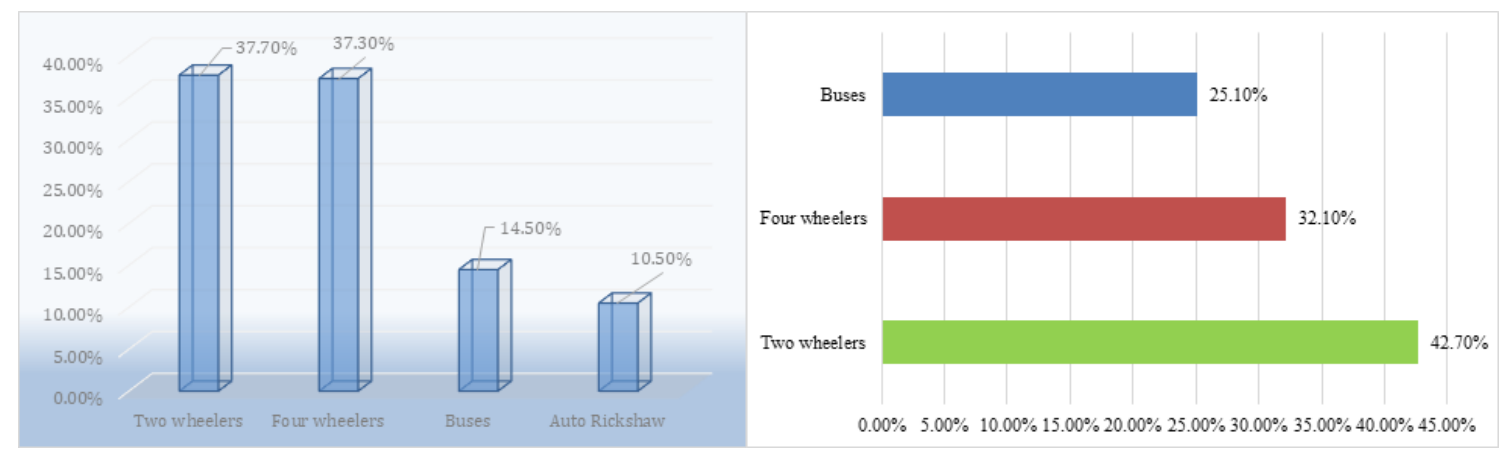


M. Durga, Paritosh Srivastava and A. Shanmuganathan

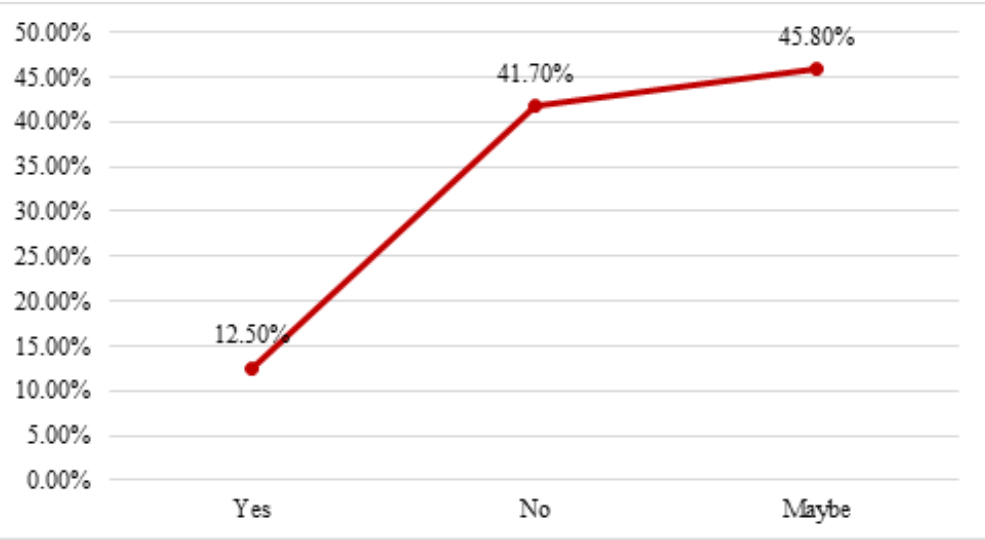

Figure 12

$37 \%$ agreed that two wheelers and four wheelers are the most common vehicles that operate in Madiwala $14.5 \%$ are buses and 10\% auto-rickshaw. Therefore, most of the participants believe that two wheelers result in most accidents followed by four wheelers. In terms of gender assessment in accordance with accident rate, almost $42 \%$ believed accidents were not caused due to gender discrimination.

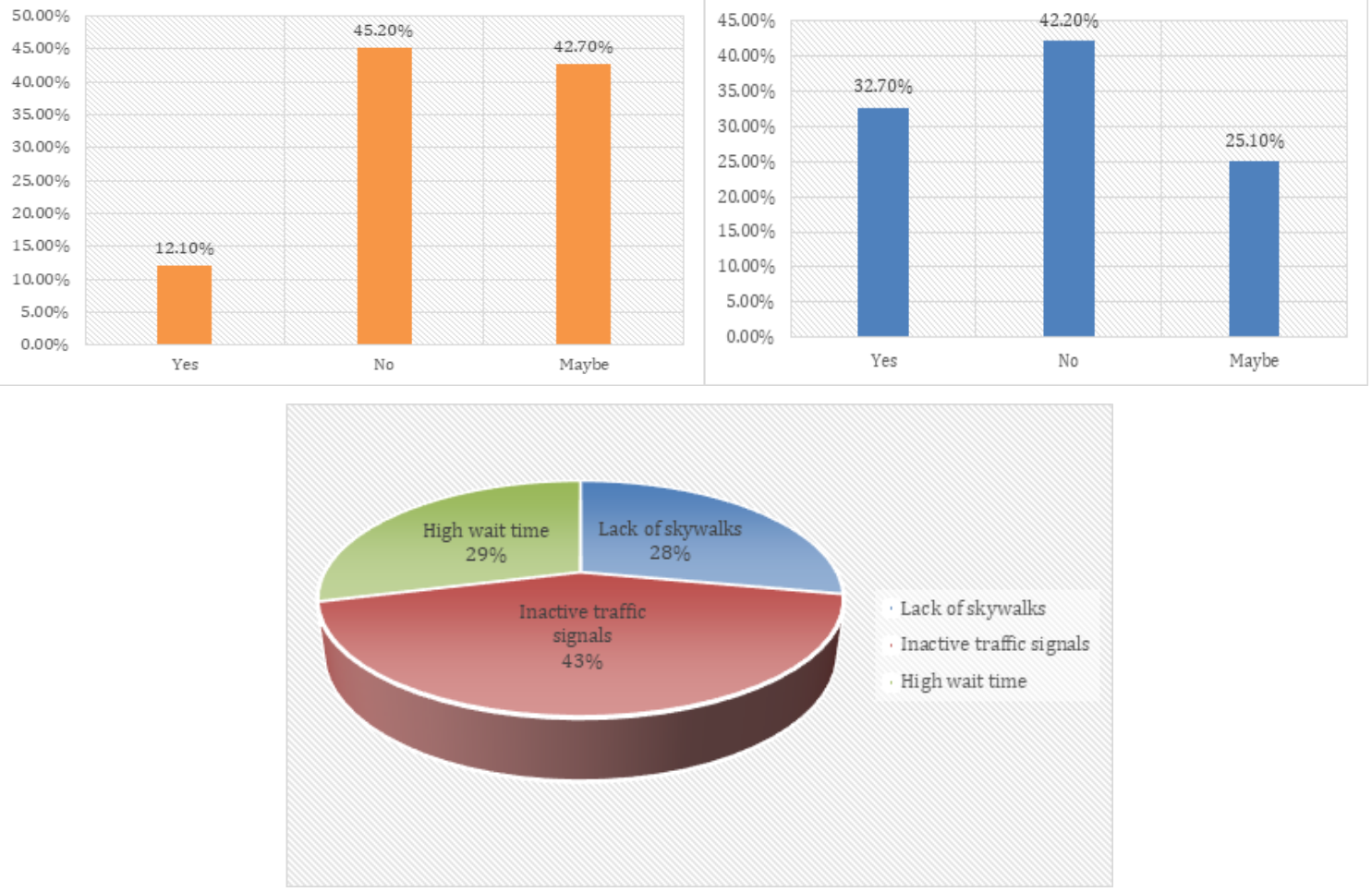

Figure 13

In accordance with the age of pedestrians affecting accidents most of the participants believe it did not result in such. On the other hand, almost 33\% agreed that the wait-time in between changing of traffic signals resulted in accidents. According to Buechel et al. (2017), adequate evaluation helped in understanding that lack of certain components. These components can be termed as inactive traffic signals and high wait time contributed to the high rate of accidents. 


\subsection{Evaluation of pedestrian's impact on Bangalore traffic}
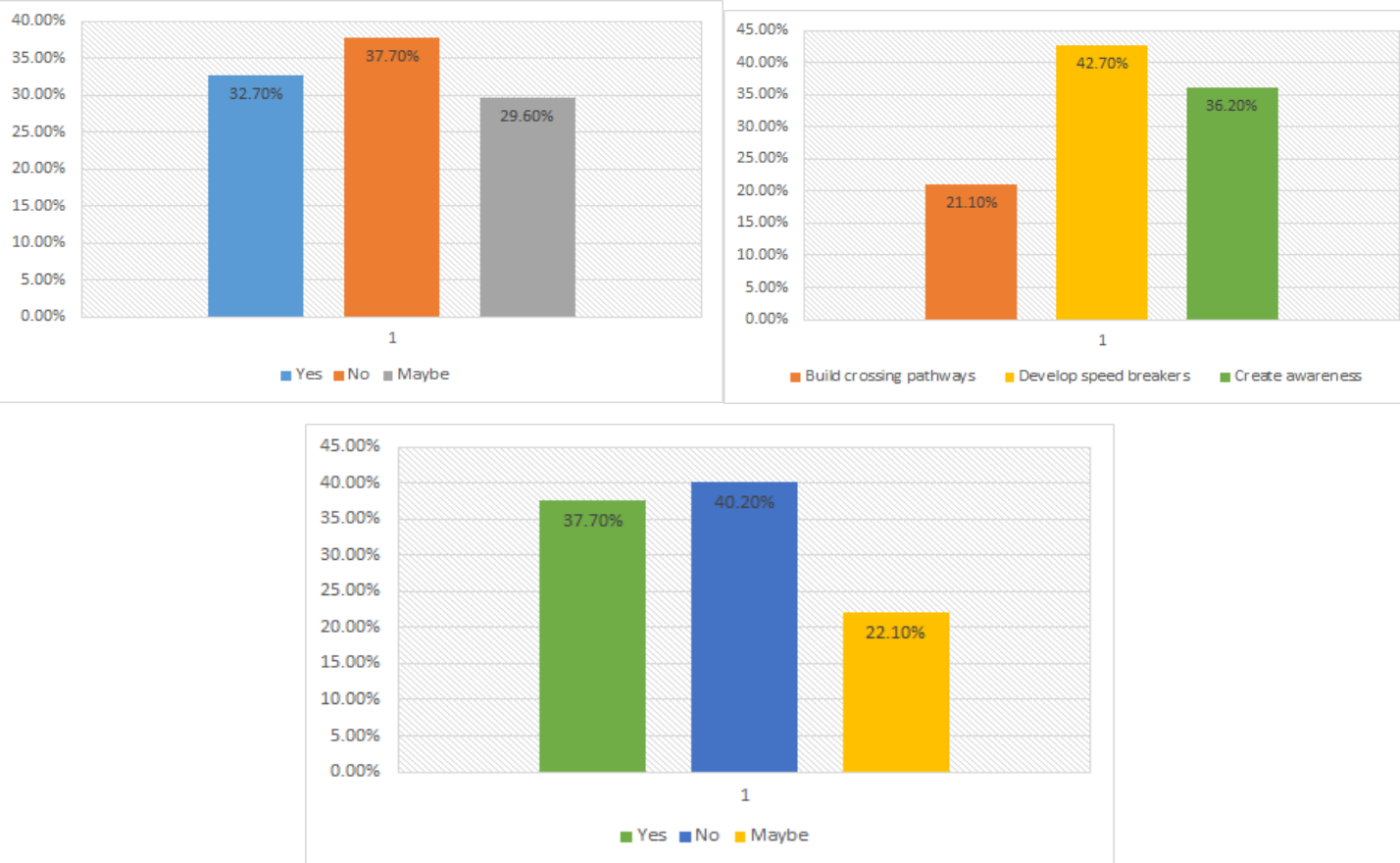

Figure 14

Almost $32.7 \%$ of the participants agreed that the cropping pattern of pedestrians resulted in accidents $29.6 \%$ considered it to be a possibility. Therefore, as per the right rate of accidents, $42.7 \%$ believed by developing speed breakers while $21.1 \%$ believed effective crossing pathways can aid towards reducing accident rate under mixed traffic conditions. This survey also helped in understanding that $40.2 \%$ of participants believed that speed of pedestrians was not a factor of accidents. Due to this effective measurement can be taken by keeping this aspect into consideration.
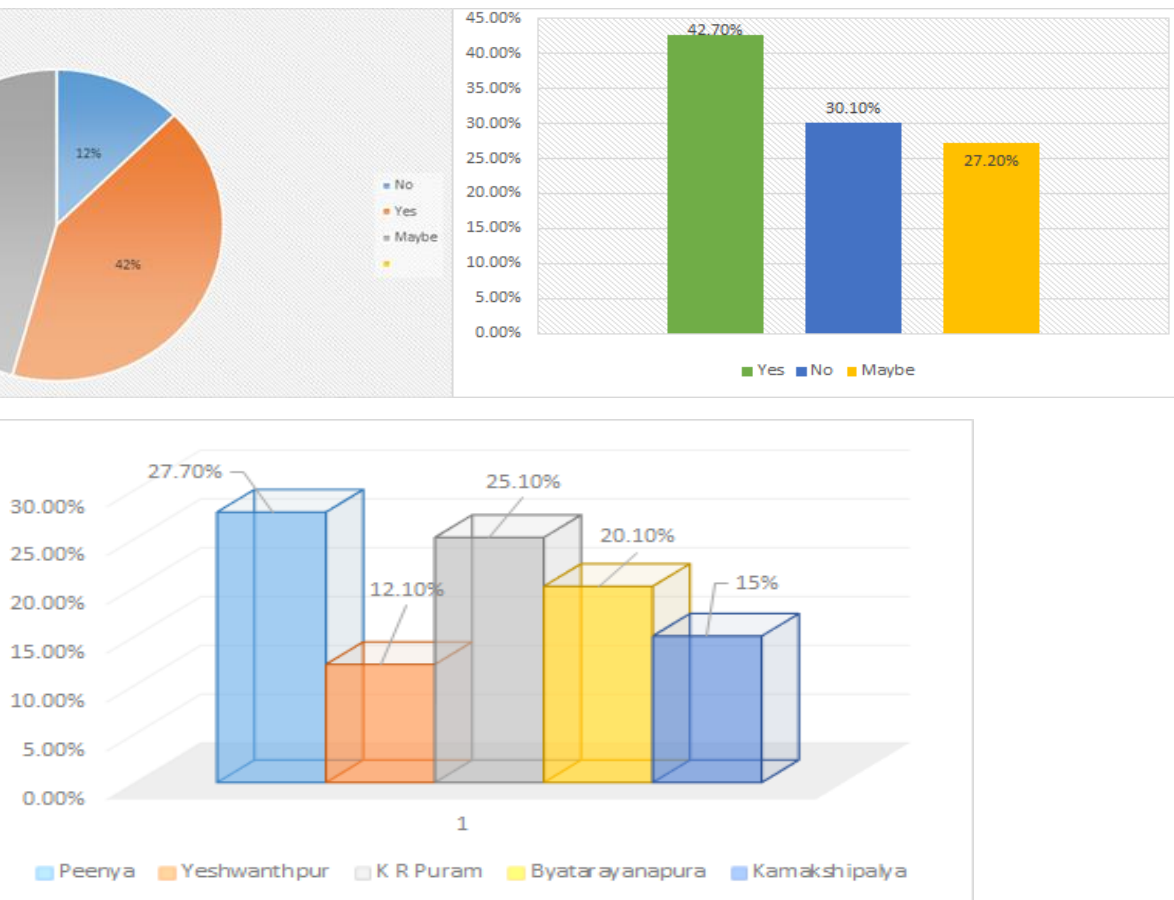

Figure 15 
The density of traffic was identified to be one of the causes catering to accidents as agreed by $41.8 \%$ of the participants. Therefore, the need for traffic officers for more closer scrutiny was needed which was agreed upon by $42.7 \%$ participants. Peenya followed by K R Puram was identified to be the most accident-prone zones in Bangalore. Due to this, effective measurements in terms of such zones can be considered of utmost importance.
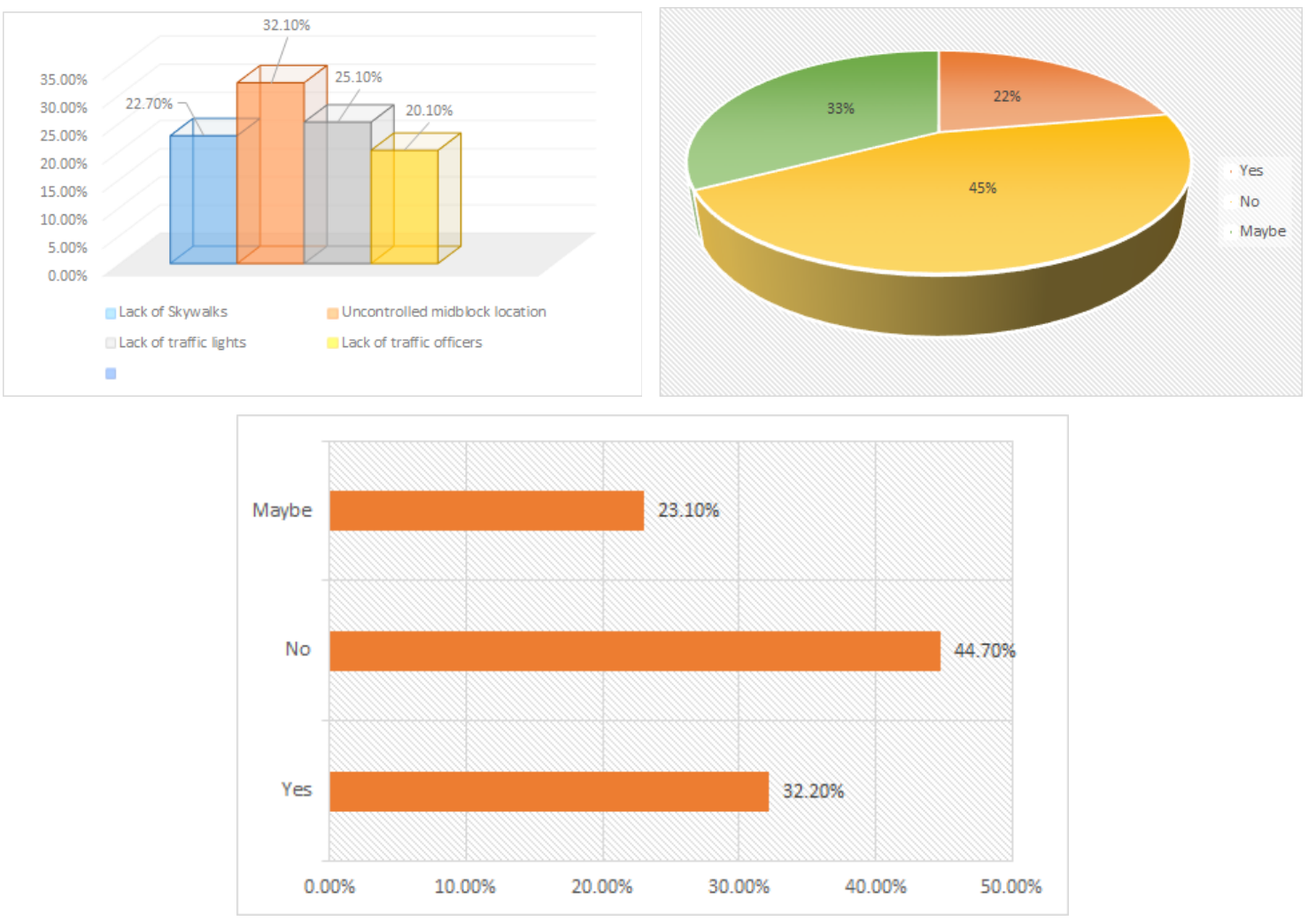

Figure 16

Most of the participants believed that uncontrolled midblock location is a common factor in accident prone zones whereas lack of skywalks and traffic light have been identified by participants respectively. In regards to the interrelationship between pedestrians and traffic movement, almost $45 \%$ believed it was not significant. One of the most crucial questions about decreasing accidents in the future resulted in a pessimistic answer where $44.7 \%$ believed it would not improve where $32.2 \%$ it would. Therefore, adequate measurements such as proper traffic rules and training of traffic offers can be asserted as appropriate measurements.

\section{QUALITATIVE DATA ANALYSIS}

\subsection{Identifying Areas Prone to Road Accidents}

An interview was conducted among four traffic officers for understanding their perspective on the increasing number of accidents in Madiwala, Bangalore. Therefore, the first question catered towards understanding their work role where it was identified that the 1st officer was posted at Swami Ayyappa junction. The second and fourth officers are responsible for managing central silk board Junction whereas the third officer for Madiwala Area. The second question aided in understanding that all the four officers believed that these four areas were dominated by heavy traffic and where congestion is a common factor.

Pedestrian flow characteristics in the third question helped in understanding that it was huge in Swami Ayyappa junction because of the large inflow of devotees. On the other hand, both the officers working in central silk board Junction agreed that there are a greater number 
of vehicles and a minimalist flow of pedestrians. However, the officer at Madiwala Area asserted that this area consists of equal inflow of vehicles and people. This can be identified to be a core reason resulting in the large number of accidents in the electronic city of Madiwala. Therefore, the need for managing pedestrians by incorporating trained constables can prove to be beneficial.

\subsection{Need for abiding by traffic rules and regulations in Bangalore}

Upon asking the rules and regulations regarding traffic law, the first and forth officer agreed that traffic was abided by in their stated locations. However, the second and third officer answered that not abiding by traffic regulations is one of the largest causes of the accidents.

In regards to the first officer, Swami Ayyappa junction within Bengaluru is a religious spot due to which there is a greater number of people while in the central silk board Junction pedestrian rate is low, however, people prefer Jaywalking which often results in difficulty in managing. However, Madiwala experiences an equal rate of traffic and pedestrians, managing pedestrian flow has been catered to as difficult since many people do not abide by traffic regulations.

The officers were also asked about their opinions regarding pedestrians as the main cause of the accidents. All officers except the officer situated at Madiwala agreed to this statement. Therefore, as influenced by Patil and Das (2018), actions regarding both aspects needed to be considered in order to manage the rate of accidents in Bangalore. Strict measurements such as implementing the penalty of the speed limit is crossed or if traffic signals are not maintained by pedestrians.

\subsection{Understanding effective measures for decreasing road accidents}

The significance of infrastructure was also evaluated by formulating effective questions along with recommendations of measurements through which accidents can be signed decreased. The first traffic officer agreed that skywalks would reduce the rate of pedestrians of the street resulting in a decrease in accidents. This was closely followed by the third officer posted in Madiwala area who also agreed to the aspect of skywalks and also added that flyovers and footpaths could be effective measures. The second and fourth officer who worked at central silk board Junction asserted that construing of pavements followed by skywalks can be helpful in prevention of accidents. According to Lobont and Tarnu (2017), inadequate infrastructure is one of the main causes of traffic accidents. This question has helped in understanding this factor due to which implementation of adequate measurements such as skywalks and pavements can help in appropriate flow of traffic and also reduce the rate of accidents.

In the last interview question, about measurements taken by the traffic officers for regulation traffic and pedestrian flow, the first officer stated that it was done by deploying traffic obstacles. The second and fourth officer agreed that traffic signals were an effective medium for controlling the flow at regulated hours. Lastly, the traffic officer at Madiwala area asserted that flow of traffic was a concerning aspect in this area. As per the view of Iwata $e t$ al. (2018), lack of effective measurements can lead to the increase in the number of accidents due to which effective measurements can be asserted as a must. This very factor was identified in the electronic city of Madiwale due to which an increase in regulatory measurements regarding traffic needs to be increased. 


\section{THEMATIC ANALYSIS}

\subsection{Evaluation of pedestrian walking flow}
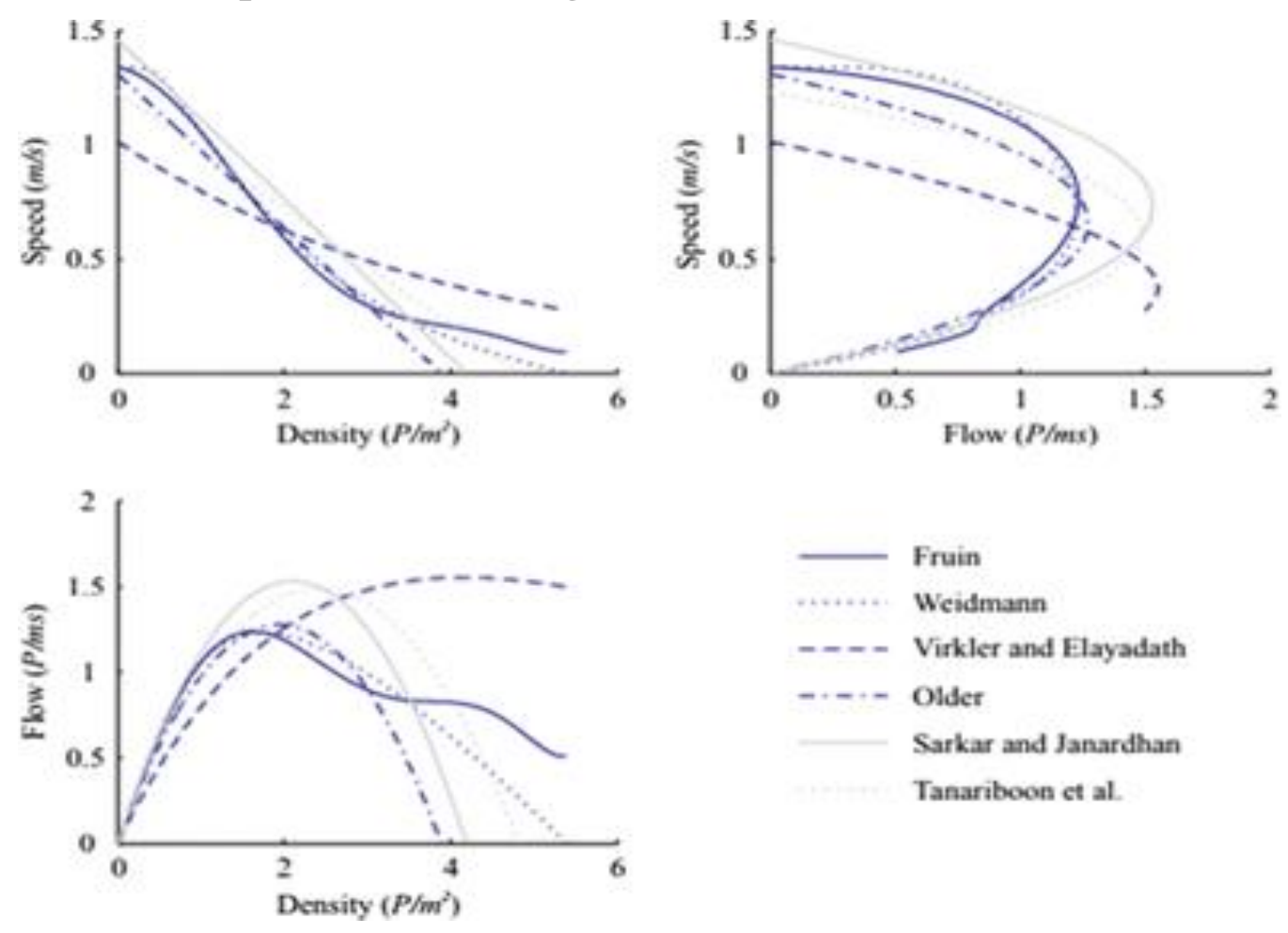

Figure 17

Thematic analysis helps in analysis of collected data by formulating common themes in order to identify recurring patterns. In the study evaluating traffic conditions of the electronic city of Madiwala in Bangalore, five themes were established.

The first theme catered towards understanding if there were inefficient variables in measuring pedestrian flow characteristics. Therefore, thorough research aided in understanding that lack of measures in terms of speed, flow and density resulted in lack of answers. According to the first theme, the need for setting of parameters and planning of infrastructure was identified as important for managing traffic conditions (Hilton et al. 2019). It has helped in understanding the significance of having structured measurements with which a high rate of pedestrian flow can be kept under control.

\subsection{Significance of traffic rules and regulation}

Theme 2 was focused on evaluating the importance of traffic rules and regulation for managing pedestrian flow. It aided in understanding that trained traffic officers are also required for maintaining a steady control. As per the second theme, traffic rules and regulations are important for curbing accidents and maintaining adequate flow of traffic. However, since these aspects are not maintained, the need for effective measurements such as imposing fines can be deemed as necessary (Vijayaraghavan and Leevinson, 2020). Due to this, incorporation of measurements in terms of traffic regulations and integrating training of traffic police can help in maintaining proper traffic control.

Theme 3 focuses on the need for construction of appropriate infrastructure in Madiwale. Adequate integration of pavements and skywalks can prove to be effective in maintaining traffic conditions. The third theme identifies that the present infrastructure in Madiwala is feasible (Padmapriya et al. 2019). Therefore, for managing traffic, especially for one-way 
traffic, adequate infrastructure such as silk board signals apart from the identified measures can prove to be fruitful.

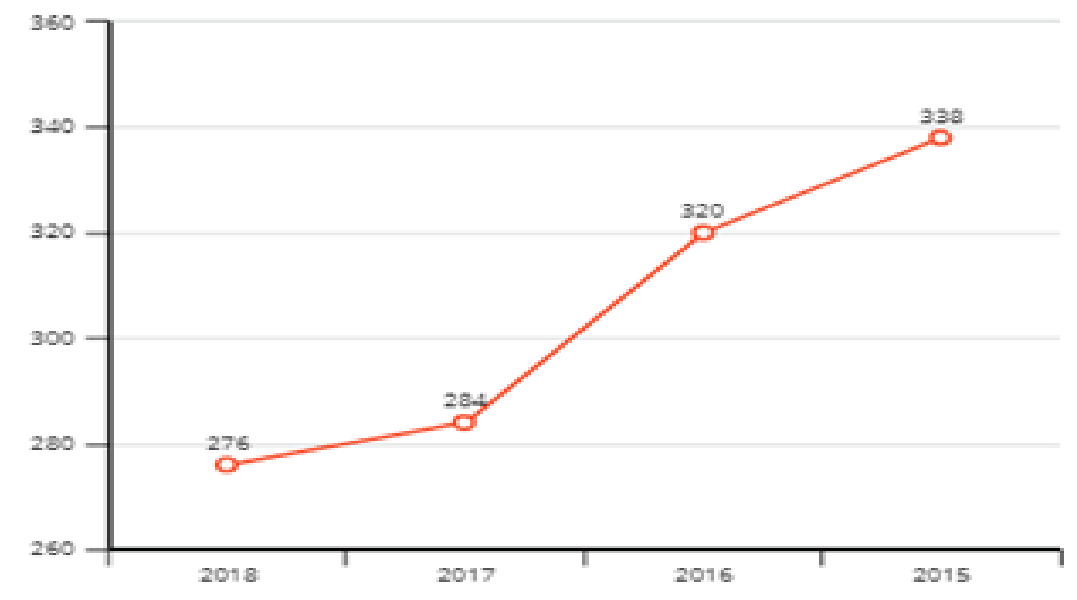

Figure 18

\subsection{Assessment of causes behind road accidents}

Theme 4 caters to the aspect of improper management of pedestrians resulting in accidents. Implementation of effective actions such as strict traffic regulations can act as a controlling measure. As per the fourth theme, almost $40 \%$ of road accidents have been identified to be because of pedestrian fault resulting in 1200 deaths in the last four years (Bhargavi et al. 2019). Evaluation of secondary data has helped in identifying that in places which have religious importance such as Swami Ayappa temple in Madiwala caters large inflow of pedestrians. Due to this, adequate traffic regulations and spreading awareness of following traffic law can aid in curbing traffic law.

Theme 5 focuses on the increased rate of population resulting in a large number of pedestrians in the road. Management of density of pedestrians is required for assessment of pedestrian influx within Madiwala. According to the fifth theme, maintaining an influx of pedestrians on the road has been observed to be difficult because of the increasing number of populations. As forwarded by Bharathi et al. (2019), Madiwala which is known as the electronic city of Bangalore is impacted due to the large number of citizens residing in the city. Along with this, various people regularly communicate due to work purposes or for visiting religious temples or places. Due to this, adequate traffic management is required to be done for maintaining the disruption within the system.

\section{CONCLUSION}

Data analysis is an essential process within a research through which adequate information can be extracted for reaching a concrete conclusion. Therefore, this chapter helped in formulating a clear view of the aspects which were the ultimate cause behind the increased rate of accidents in the electronic city of Madiwala in Bangalore. Upon conducting primary and secondary data analysis, one of the common factors identified was the high rate of traffic. Not abiding by traffic law by both citizens and drivers resulted in accidents was also observed to be one of the reasons. Lack of skywalks or pavements along with no such stable measurement of pedestrian flow resulted in the increased number of accidents. Therefore, the importance of taking immediate actions have been identified through this analysis. Effective measurements such as modified regulations in terms of traffic signals, training for traffic police and adequate infrastructure can help in eradicating such problems. 


\section{REFERENCES}

[1] Bbc.com (2016). Why is Bangalore stuck in traffic jams?. Available at: https://www.bbc.com/news/world-asia-india-38155635 [Accessed on: 29 April 2020]

[2] Bharathi, N., Malghan, D.V. and Rahman, A., (2019). Village in the City: residential segregation in urbanizing India. IIM Bangalore Research Paper, (588).

[3] Bhargavi, S., Niranjan, S., Bhat, R., Sameera, L.R. and Shaw, S., (2019). Intelligent Traffic System for Auto Detection of Traffic Rules Violation and Intimation with Pollution Monitoring. Perspectives in Communication, Embedded-systems and Signal-processingPiCES, 2(12), pp.294-296.

[4] Buechel, M., Hinz, G., Ruehl, F., Schroth, H., Gyoeri, C. and Knoll, A., (2017). Ontologybased traffic scene modeling, traffic regulations dependent situational awareness and decisionmaking for automated vehicles. In 2017 IEEE Intelligent Vehicles Symposium (IV) (pp. 14711476). IEEE.

[5] Hilton, S., Cairola, F., Gardi, A., Sabatini, R., Pongsakornsathien, N. and Ezer, N., (2019). Uncertainty quantification for space situational awareness and traffic management. Sensors, 19(20), p.4361.

[6] Hooftman, N., Messagie, M., Van Mierlo, J. and Coosemans, T., (2018). A review of the European passenger car regulations-Real driving emissions vs local air quality. Renewable and Sustainable Energy Reviews, 86, pp.1-21.

[7] Iwata, T., Otsuka, T., Shimizu, H., Sawada, H., Naya, F. and Ueda, N., (2018). Finding appropriate traffic regulations via graph convolutional networks. arXiv preprint arXiv:18(10).pp.12-97.

[8] Lobont, L. and Tarnu, L.I., (2017). An empirical analysis of the relation between infrastructure and road accidents. In MATEC Web of Conferences (Vol. 121, p. 06005). Les Ulis: EDP Sciences.

[9] Padmapriya, V., Ashok, A.K., Sujatha, D.N. and Venugopal, K.R., (2019), February. Road Side Unit assisted Emergency Vehicle Transit Approach for Urban Roads using VANET. In (2019) IEEE International Conference on Electrical, Computer and Communication Technologies (ICECCT) (pp. 1-6). IEEE.

[10] Patil, A. and Das, D., (2018). Comparative Analysis and Suggestion of Architectures for Reduction of Road Accidents. International Journal of Civil Engineering and Technology, 9(3).

[11] Subrahmanya, M.B., (2017). Comparing the Entrepreneurial Ecosystems for Technology Startups in Bangalore and Hyderabad, India. Technology Innovation Management Review, $7(7)$.

[12] Vijayaraghavan, V. and Leevinson, J.R., (2020). Intelligent Traffic Management Systems for Next Generation IoV in Smart City Scenario. In Connected Vehicles in the Internet of Things (pp. 123-141). Springer, Cham. 